\title{
Design of Radial Artery Pulse Sensor System for Ayurveda Disease Diagnosis
}

\author{
Narendrakumar, K B Ramesh
}

\begin{abstract}
In today's modern world everyone will be suffering from one or another disease and to know it all doctors suggest to undergo some scanning like $x$-ray, MRI, city scan and some blood checkups to confirm one's health issue with his prediction. In ancient days there was no scanning and checkup instead people believed in physicians, who use treat the unhealthy persons with knowledge of medicine known as ayurveda in India and Traditional Chinese Medicine (TCM) in china.

In ayurveda there are eight methods to diagnose the health status and one of it is nadi pareeksha, where nadi vaidya feels the three nadi signals vata, pitta and kapha at the wrist of a person and by feeling the palpation of these signals he predicts the health status of a person. As now a day's everyone has adopted costly and complex foreign medicine, which only tries to cure the present health issue of a subject has got hundreds of side effects, so in order to overcome this we need to follow the ayurveda practitioner. Ayurveda require a very experienced person who rarely seen in modern world, so we are trying to bring their ideas in some technical views.

In this project, a non-invasive methodology is implemented to know health issue of a person and an attempt is made to bring back the ayurvedic knowledge. Where nadi signals of a subject are acquired and calculated each signal mean and peak values, which are different for different health issues and stored in a database. The incoming new subject signals mean and peak values are computed and compared with values stored in data base and then the system reports the health status of a subject.
\end{abstract} card

Keywords: Pulse diagnosis, Wrist pulse signal, nadi, DAQ

\section{INTRODUCTION}

Throb investigation is an antiquated Ancient medical treatise structure of fortitude through the weary. It can indeed scrutinize both corporeal and psychological ailments and also lopsided physiognomies. The term throb alludes to the weary, nerves, veins, progressions and some kind of canal entry of physiological and carbon-based signs. Throb analysis restraints you about potential wellbeing dangers.

Revised Manuscript Received on December 12, 2019.

Narendra Kumar, Assistant Professor, Affiliated to R.N. Shetty Institute of Technology,Bengaluru,Karnataka

K B Ramesh, Affiliated to R.V College of Engineering,

Bengaluru,Karnataka

It gives you an empathetic on the most proficient method to enhance your wellbeing as per the components which are overwhelming in your physique. It gives you a customized and individual visualization which is itemized and precise. A few constant infections like diabetes, barrenness, weight, and hypertension, loss of motion, mental issue, extreme joint torments and skin maladies can be illustrious by employing this throb analysis. We can recognize vitality blockages through heartbeat focuses and that is the means by which one can realize what the issue is. The early morning is the best time to check the pulse, physiologically the slightest dynamic time. Three extremities are exploited to check weary concentrations, the fore finger, middle finger and ring finger with the pointer set adjoining to the wrist furrow. At to start with, the three loci are palpated all the while, at first, gently, then with medium encumbrance, lastly all the more firmly. After this, every spot is checked individualistically. Diverse frameworks are utilized whereby the weary at every locus is allied to unambiguous organs as displayed in Fig (1).

At the point when the weary is taken, contemplation is certain to the recurrence, abundancy and nature of the beat. A conventional heartbeat is inimitable, perceptible to the sensitized upon medium encumbrance, can even now be palpated with the use of overwhelming encumbrance. Yong Jun et al. [8] designed a resonator based sensor system to acquire radial artery pulses. Here reflection coefficient of signal is focused USING wearable communication devices. The received signal reflects the required pulse variations for clinical purposes. Zuo et al. [9] confirmed signal extraction using pressure sensors, photoelectric sensors and Ultrasonic sensors. according to the physical meanings, correlations of the acquired signal from these three sensors, and sensitivity factors. According to modern medical theory, the patients "e wall of the vessel is different from that of healthy people; thus the signal of pulse taken from the optical sensor has useful information for detecting health abnormalities. A well trained nadi Analyst identifies more than 300 different disease conditions based on the dominant pulse motion and its direction. The key to identification of the ailment is to study the relationship between pulse pattern[2]. The ratio of vata, Pitta, kapha in a healthy human being is 4:2:1 respectively. This ratio follows seasonal variations and changes with parameters such as time of the day, temperature and humidity of the skin. According to the Ayurvedic practitioner the right arm of male subjects and left arm of female subjects is used to read the pulse. 


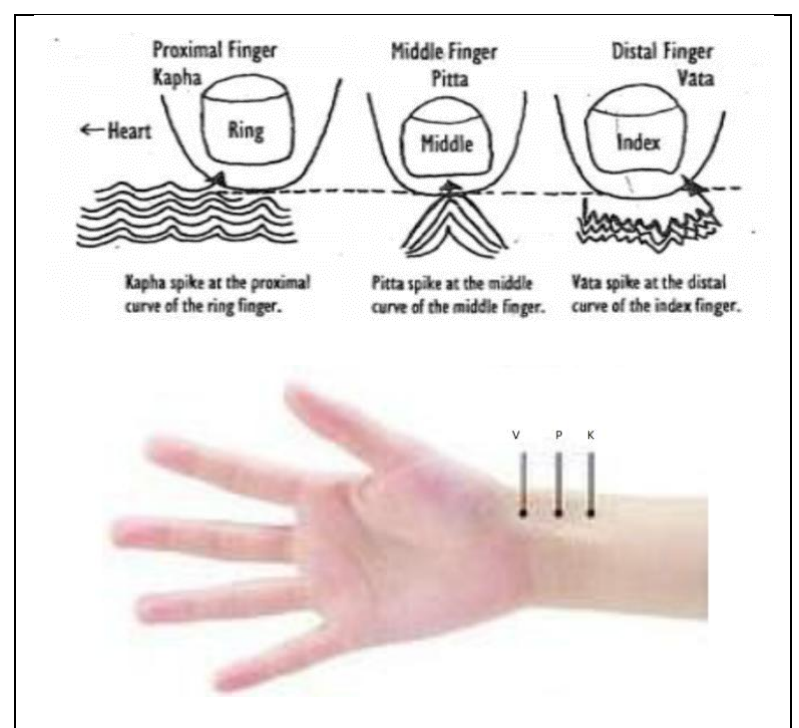

Figure 1: The positions of Pulse Diagnosis

Table 1, indicates the characteristics of three pulses using eight parameters like location, rate, rhythm, tension and volume, temperature, so on.

Table 1: Characteristics of Pulses

\begin{tabular}{||l||l||l||l||}
\hline \hline & $1^{\text {st }}$ Pulse & $2^{\text {nd }}$ Pulse & $3^{\text {rd }}$ Pulse \\
\hline \hline Location & Index & Middle & Ring \\
\hline Frequency & $80-95$ & $70-80$ & 50-60 \\
\hline \hline Regularity & Irregular & Regular & Regular \\
\hline \hline Amplitude & Low + & High +++ & $\begin{array}{l}\text { Moderate } \\
++\end{array}$ \\
\hline \hline Gait & $\begin{array}{l}\text { Quick and } \\
\text { leaps like a a } \\
\text { frog }\end{array}$ & $\begin{array}{l}\text { Prominent, } \\
\text { strong, high } \\
\text { amplitude, } \\
\text { like snake }\end{array}$ & $\begin{array}{l}\text { deep, slow, } \\
\text { broad, like } \\
\text { elephant }\end{array}$ \\
\hline \hline $\begin{array}{l}\text { Tension and } \\
\text { Volume }\end{array}$ & Low & High & Moderate \\
\hline \hline Temperature & Cold & Hot & $\begin{array}{l}\text { Warm to } \\
\text { cool }\end{array}$ \\
\hline \hline Vessel wall & $\begin{array}{l}\text { Rough, } \\
\text { hard }\end{array}$ & $\begin{array}{l}\text { Elastic, } \\
\text { flexible }\end{array}$ & $\begin{array}{l}\text { Soft } \\
\text { thickening }\end{array}$ \\
\hline \hline
\end{tabular}

\section{RELATED WORKS}

[6] Differential pressure sensor is described in a measurement system, where a feeble kapha pulse is measured with strain gauges.

Gagnadre et al., [7] The fiber optic sensors are used in measuring heart rate. Photo detectors where use in measuring pressure variations .It works on the basic principle of modal distribution in fibre due to pressure of the pulse.

The dataset is acquired from the acquisition system designed using graphical coding techniques.

Fig. 4 shows the pulse signal acquisition device. The signal sampling rate is 14400 samples/sec. vatha, pitta, and khapha signals are collected from wrist locations of 50 healthy individuals and 10 patients. By moving the acquisition hardware during the acquisition of the radial pulse signal different levels of pressure are imposed on the radial artery The raw continuous signal of "Vatha" and "pittha" and "khapha" of the wrist are acquired .

\section{Our Pulse Measuring System}

A signal conditioning unit is used to improve the quality of acquisition. It includes amplification, filtering, noise reduction Pulse detection and feature extraction is done using labVIEW.DSP techniques are used to extract time and frequency features.FFT technique is used to convert time and frequency domain. Frequency of pulses are measured using spectral analysis where maximum value of the spectrum is frequency of that particular nadi signal vata,Pitta and kaphaPatterns of nadi pulses will be extracted individually and patterns are validated using predefined nadi patterns and style

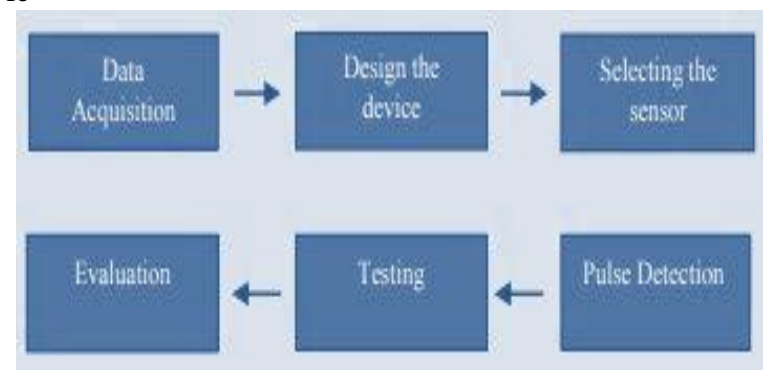

Figure 2: Basic block diagram of the pulse acquisition

The electronic set up for acquiring radial pulses from the predefined points of the wrist is initially tested with test signals and found error free signal using Photo plethysmo graphy (PPG).

A band is firmly held at these three points for recording purpose. The data is collected from 50 healthy subjects in the age group of $20-30$ who had no history of cardio vascular disease. The recording was done 3 times a day for each subject. all the subjects were asked to provide daily routine and life style which indicates their body type with respect to doshas as per Indian tradition system. Signals were acquired at the rate of 14400 samples/sec.one pulse at a time is recorded vata,pitta and kapha respectively and then analysis was done.

Following steps are used for Data acquisition:-

Step 1: The subjects under test were made to relax for 10 minutes before data acquisition

Step 2: The subjects were asked to sit on a chair and stretch hand comfortably to the level of heart for better data acquisition

Step 3: The sensor strip or band is first raised at points of vata, pitta and kapha respectively as shown in the figure 1 and figure 6.

Step 4: The vata signal and the kapha signal were taken by the sensors at the $2^{\text {nd }}$ and the $3^{\text {rd }}$ nadi points. All the three nadi signals are recorded at the same sampling frequency 14400 samples/sec.

Step 5: At room temperature. The nadi signal is acquired and saved three times a day for each person..

\section{A. Sensors}

Optical pulse sensors are used to acquire pulse signals from the subject,as shown in the Fig 3. The sensor has a light source that sends light into the pointed nadi capillary tissue and a photo sensor reads the amount of light back from the tissue . This method is popularly known as Photoplethysmography. 


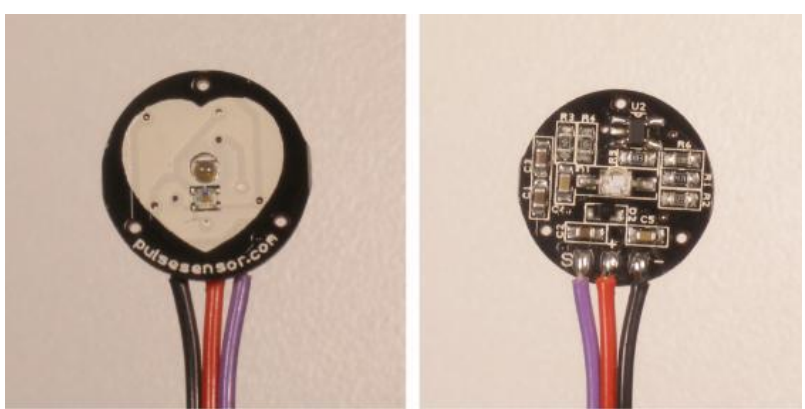

Fig 1 : Optical sensor front and back images respectively

Pulse sensor is placed at appropriate points on the radial artery as shown in Fig 1. Sensors are positioned carefully where the arterial pulsation occurs, as incorrect positioning will lead to incorrect output. Thus, the placement of the sensors an important factor for acquisition.

\section{B. Embedded board myRIO-1900}

National Instruments myRIO-1900, shown in Fig 4 and Fig 5, is an embedded, portable reconfigurable I/O (RIO) device. It has an on-board 12-bit resolution Analog-to-Digital Converter and a microcontroller to execute LabVIEW code. Filtering and analysis of digitized data takes place on-board. Sensors are connected to a MXP connector.
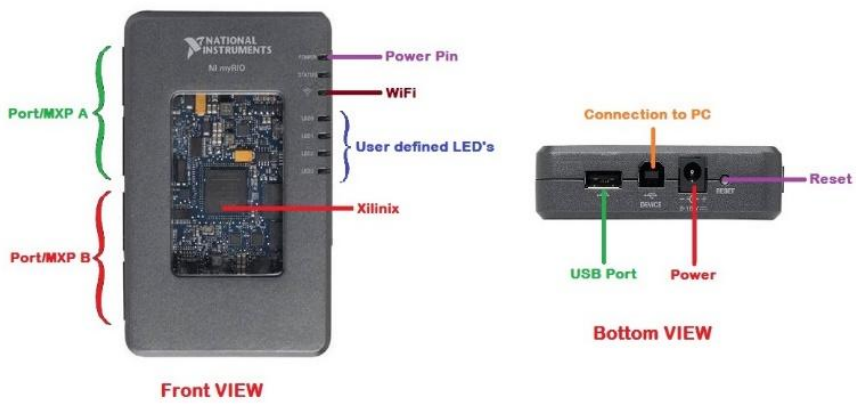

Fig 2a: Front view and side view of myRIO-1900 respectively

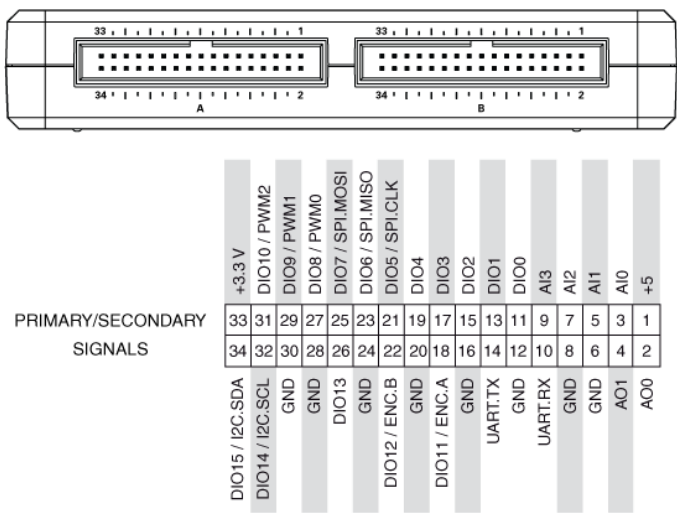

Fig 4b: Side view of myRIO-1900 showing MXP connectors

\section{Pre-processing of pulse signals}

Contamination of nadi signals by noise due to channel nonlinearities (high frequency) and due to muscular motion of hand during acqiusition (low frequency) is common. There is also the problem of optical noise resulting due to reflection of incident light on skin, muscles, bone and cartilage during signal acquisition. Hence, the need for design of a suitable frequency response with the following specifications:

- Lower cutoff frequency $-0.125 \mathrm{~Hz}$

- Upper cutoff frequency $-60 \mathrm{~Hz}$

The maximum frequency of pulse signals are approximately $50 \mathrm{~Hz}$. Therefore, the cut-off frequency of the filter is set as $60 \mathrm{~Hz}$.

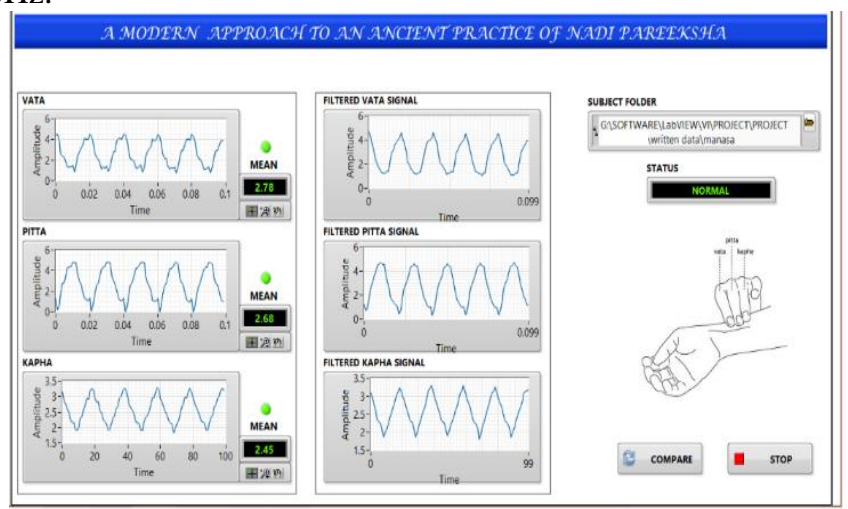

Figure 5: waveforms of the pulse acquisition

\section{Analysis of pre-processed signals}

We obtain the FFT and power spectrum graphs of the pre-processed signals. From these graphs, we can observe basic Nadi waveform pattern for Vata, Pitta and Kapha and signal variation for each individual.

\section{EXPERIMENTAL RESULTS}

Fig 6 shows the prototype of the proposed system. The three sensors placed on the radial fossa artery, left arm for men and right arm for women.

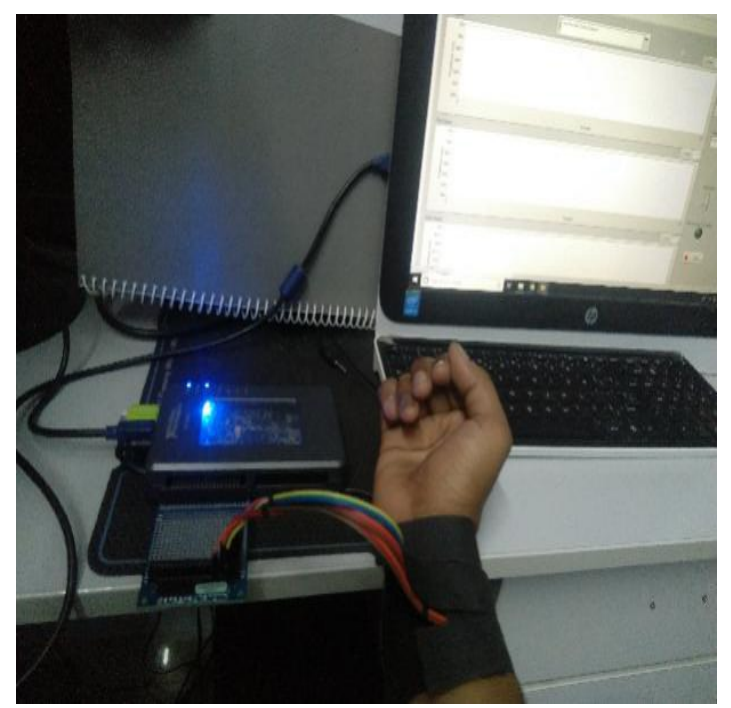

Fig 3: Nadi pulse acquisition system

Figure 7 shows the nadi pulse signals acquired from optical pulse sensors using LabVIEW.

Published By:

Blue Eyes Intelligence Engineering DOI: 10.35940/ijitee.B1126.1292S19 


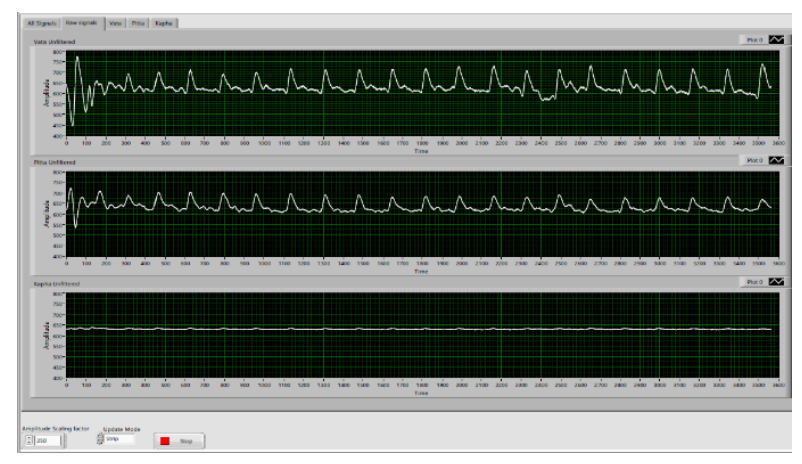

Fig 4: Nadi unfiltered signals from optical sensors The Nadi pulse signal are filtered, their Fast Fourier Transforms and power spectrum signal graphs are shown for Vata, Pitta and Kapha signals in Fig 8, Fig 9, and Fig 10 respectively.

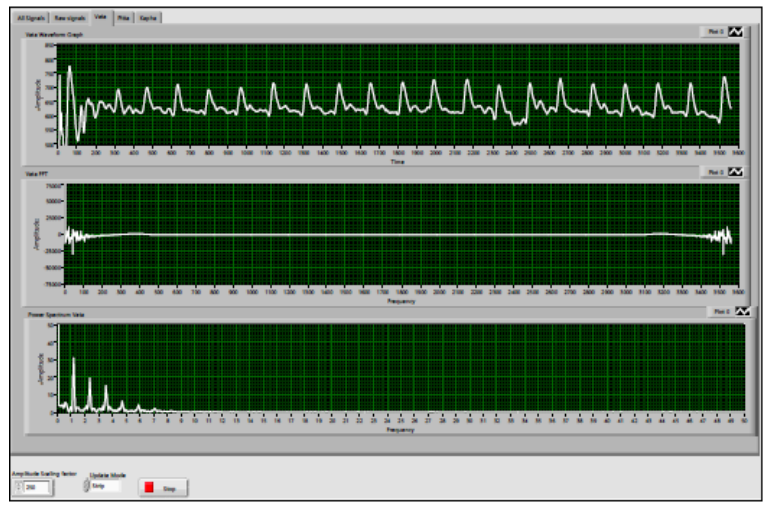

Fig 5: Filtered Vata signal, FFT and power spectrum

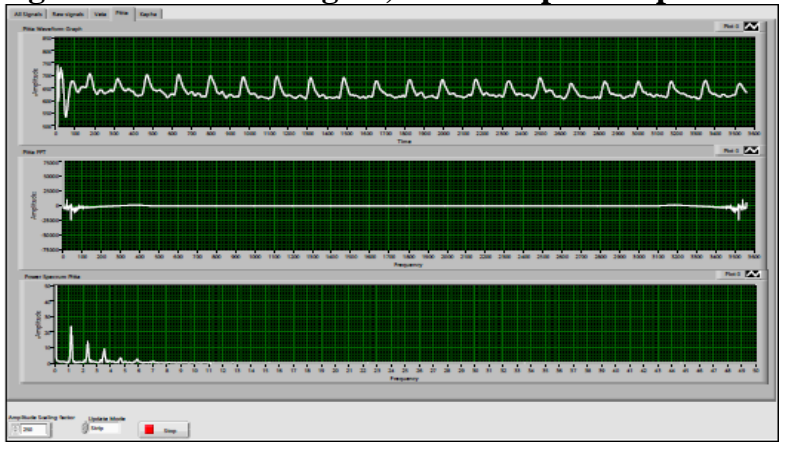

Fig 6: Filtered Pitta signal, FFT and power spectrum

\section{STATISTICAL ANALYSIS AND CLASSIFICATION}

Ten feature values obtained for detection of a healthy and unhealthy person increase complexity. To reduce the number of features and determine useful and significant features, they were analyzed statistically for finding the best feature or combination of features for distinguishing between healthy and unhealthy subject. Analysis of variance e was performed and features were named 1 to 10 according to bands.. So, these were analysed as significant features from 10 features which could be used for distinguishing between healthy and unhealthy person as shown in Table 2.

$$
\begin{array}{lllllll}
\text { Classifier } & \text { F4 } & \text { F1 } & \text { F7 } & { }_{1} & \text { F4+F } & \text { F4+F1+F7 }
\end{array}
$$

\begin{tabular}{|c|c|c|c|c|c|c|c|}
\hline Classifier & & F4 & F1 & & F7 & $\mathbf{F} 4+\mathbf{F}$ & $\mathrm{F} 4+\mathrm{F} 1+\mathrm{F} 7$ \\
\hline KNN & 4 & 95.1 & 95.8 & 78 & 86.8 & 97.77 & 96 \\
\hline SVM & 3 & 91.5 & 88.8 & 2 & 71.0 & 97.77 & 96 \\
\hline LDA & 4 & 87.6 & 70.0 & & 70.8 & 97.77 & 96 \\
\hline QDA & 8 & 91.4 & 70.2 & 4 & 69.6 & 92 & 96 \\
\hline DT & 4 & 95.1 & 85.8 & 6 & 74.0 & 97.77 & 96 \\
\hline
\end{tabular}

than the other two pulses.

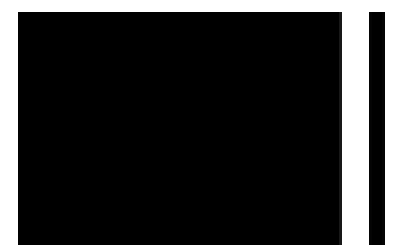

Figure10: The variation of the pulse rate during morning, afternoon and evening of a typical subject.

Table 3: amplitude of pulse with time of the day

\begin{tabular}{|c|c|c|c|}
\hline $\begin{array}{c}\text { Pulse amplitude } \\
\text { in (mvolts) }\end{array}$ & Vata & Pitta & Kapha \\
\hline Morning & 900 & 700 & 500 \\
\hline Afternoon & 950 & 410 & 560 \\
\hline Evening & 800 & 400 & 380 \\
\hline
\end{tabular}

The amplitude and frequency analysis was done for subjects and is shown in table.

\section{RESULTS AND DISCUSSION}

Graphical User Interface (GUI) is a platform that allows user to interact with electronic instrument through some images than texts. GUI gives the information available to user through graphical icons and visual indicators such as secondary notations, opposed to text-based interfaces, typed labels or text navigations. The term GUI is historically restricted to the scopes of two-dimensional displays screens with display resolutions able to describe generics information. 
Data acquisition Initial step in methodology is to acquire the nadi signals from a subject, GUI shown below figure 5.1 displays nadi signals of a subject in real time as we connect sensor to the wrist of subject. As three sensors are connected to wrist, parallaly all the three vata, pitta and kapha signals can be read and displayed simultaneously

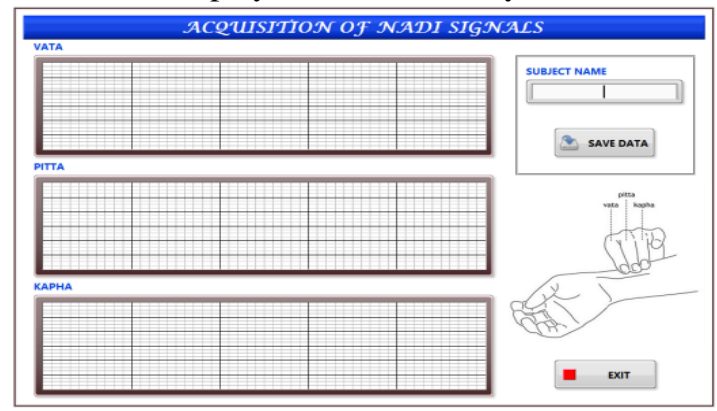

Figure12: GUI for acquisition of nadi signal

\section{Mean Detection}

GUI figure14 shown below displays two sets of graph indicator where one shows the vata, pitta and kapha acquired nadi signals and other shows the filtered nadi signals along with their mean value for a particular subject chosen from database.

GUI shows the result of a subject's health status after matching his vata, pitta and kapha signal mean value with the mean value range defined for whole data base and when it falls in rules defined for NORMAL then it indicates his health status as NORMAL.

.A particular subject who is suffering from cold, his signals are selected and all his three signals mean values are checked with mean value rules defined for different disease. GUI figure shows that his mean values fall in range defined for COLD and the results shows that he is suffering from COLD.

GUI figure 14 shown below indicates results for a subject who is suffering from FEVER, as his signals are stored in data base and signal are called through the folder name and mean of all the three nadi signals is measured and matched. GUI shows the results as FEVER as his signals mean value falls in the range specified for FEVER

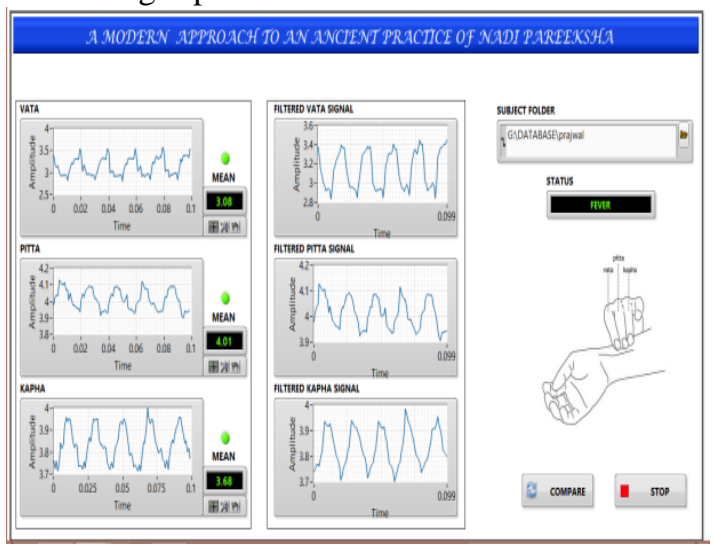

Figure 14: Nadi signals for FEVER with mean values

GUI figure15: gives the results for a subject who is pregnant as we acquired her nadi signals and computed mean for all the three signals, which got matched with mean ranges specified for PREGNANT.

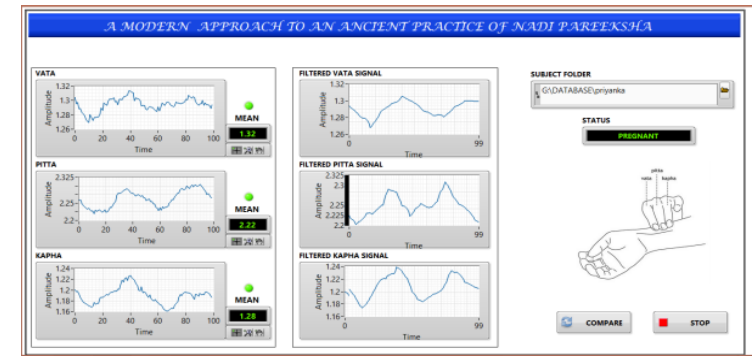

Figure 15: Nadi signals for PREGNANT with mean values

Nadi signals for different health status can be compared with NORMAL person nadi signals; GUI figure 5.8 shown below compares the Normal signals with signals of COLD.

Pattern Matching

This shows the results for pattern matching methodology; this technique is used to detect the NORMAL, COLD AND FEVER health conditions of a subject. In order to cross check peak detection results it is compared with mean detection results. In GUI left side graph indicator set shows nadi signals of a person with their mean values and a set of graph indicators at right side shows the peak points of the signal. A normal subject signals are acquired when it is compared with mean range and peak range defined in database, in both the case subject's signals fall in the range defined for NORMAL condition, GUI shown gives the health status of a subject as NORMAL.

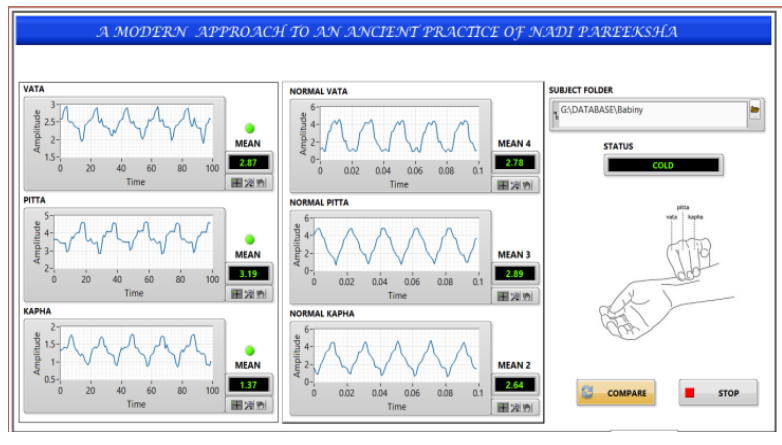

Figure 16: Nadi signals comparison for NORMAL and COLD

GUI results for a subject who is suffering from FEVER, as their nadi signals mean and peak values got matched with the ranges specified for FEVER

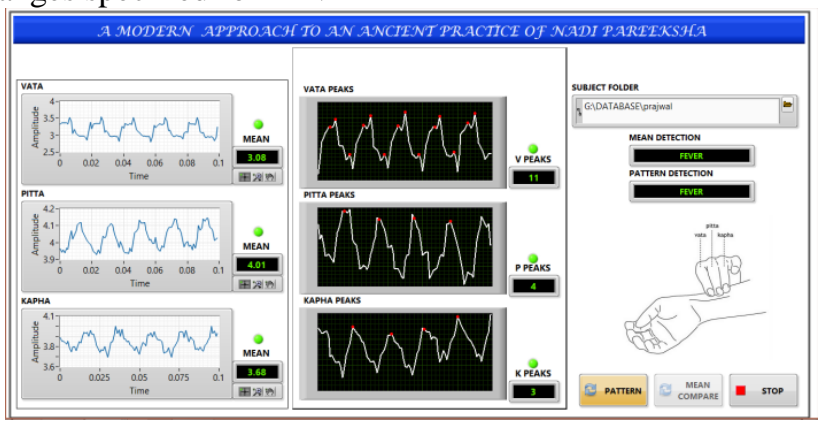

Figure 17: Nadi signals for FEVER with peak values 


\section{CONCLUSION AND FUTURE WORKS}

According to ancient literature there is not a single disease in the human body which can't be diagnosed by examining the pulse; this intern says that it is possible to know the pathologic condition of any person by checking his wrist pulses, but to rely on this, one need to have years of experience in order to diagnose disease.

In this project a non-invasive methodology is implemented to know health status of a person in a system. Nadi' $s$ three signals vata, pitta and kapha signals are acquired from different subjects having different health status through sensor and acquiring device to create data base of different know health status.

Mean detection and pattern recognition methodologies are used to classify the health status of a subject. In mean detection method mean values are computed, then compared with that stored in database. In pattern recognition methodology number of peak values are computed and compared with database values, then health status of a person is detected.

Table 4 given below shows the number of signals acquired and properly classified signals for different disorders using Mean Detection method

\begin{tabular}{|l|l|l|l|}
\hline $\begin{array}{l}\text { Total } \\
\text { Signals in } \\
\text { Database }\end{array}$ & $\begin{array}{l}\text { Name of the } \\
\text { disorder }\end{array}$ & $\begin{array}{l}\text { Number of } \\
\text { signals for } \\
\text { different } \\
\text { disorder }\end{array}$ & $\begin{array}{l}\text { Classified } \\
\text { Properly }\end{array}$ \\
\hline \multirow{3}{*}{35} & Normal & 11 & 11 \\
\cline { 2 - 5 } & Cold & 7 & 6 \\
\cline { 2 - 5 } & Fever & 4 & 4 \\
\cline { 2 - 4 } & Back pain & 3 & 3 \\
\cline { 2 - 4 } & Pregnant & 2 & \\
\hline
\end{tabular}

Table 5 shows the results obtained by performing pattern recognition

\begin{tabular}{|l|l|l|l|}
\hline $\begin{array}{l}\text { Total } \\
\text { Signals in } \\
\text { Database }\end{array}$ & $\begin{array}{l}\text { Name of the } \\
\text { disorder }\end{array}$ & $\begin{array}{l}\text { Number of } \\
\text { signals for } \\
\text { different } \\
\text { disorder }\end{array}$ & $\begin{array}{l}\text { Classified } \\
\text { Properly }\end{array}$ \\
\hline \multirow{3}{*}{35} & Normal & 11 & 10 \\
\cline { 2 - 5 } & Cold & 7 & 6 \\
\cline { 2 - 4 } & Fever & 4 & 4 \\
\hline
\end{tabular}

From mean detection methodology we obtained efficiency of $96.29 \%$ and using pattern recognition methodology efficiency is $90.9 \%$.

In current work data base was created only for few health status. As an enhancement of present work the data base can be enriched with various health statuses of known and unknown disorders. It will also be very helpful for diagnosing any new disorders in future compared to other conventional invasive methods.

\section{ACKNOWLEDGMENT}

The authors thank Dr. Punith and Dr.Sanmathi for their valuable inputs related to Ayurveda, also I would like to thank Dr Arvind H S for his continuous support in the field of Embedded Systems.

\section{REFERENCES}

1. SarvadevaUpadhyaya, "Nadi Vijnaana", First Edition, Vedic Life Sciences Pvt. Ltd., 1986.

2. Vasant D. Lad, "Secrets of the Pulse: The ancient Art of Ayurvedic Pulse Diagnosis", MotilalBanarsidass 2005.

3. Herztman, "Photoelectric Plethysmography of the fingers and toes in man", [Proceedings of the Society for Experimental Biology and Medicine 37:1622-1637 (1937)

4. Sorvoja H. et.al. Licentiate Thesis, University of Oulu (1998--in Finnish).

5. Ruha et al., in Proceedings of Biosignal 1:198-200 (1996)

6. Dupuis \& Eugene, in "IEEE Transaction on Instrumentation \& Measurement", 49:498-502 (2000)

7. Gagnadre et al., in Electronic Letters, 32:19911993 (1998)

8. Jun, Y., Yun, G.H., Kim, S.W., Yook, J.G., 2014, Wrist pulse detection system based on changes in the near-field reflection coefficient of a resonator, IEEE Microwave and Wireless Components Letters, 24(10), pp. 719-721.

9. Zuo, W.M., Wang, P., Zhang, D., 2016, Comparison of three different types of wrist pulse signals by their physical meanings and diagnosis performance, IEEE journal of biomedical and health informatics, 20(1), pp. 119-127.

10. Dong, H.X., Lu, P., Wang, X., 1999, Hemorheological changes and its clinical significance in patients with operable lung cancer, Journal of Chinese Microcirculation, 1999(4), pp.5.

11. Elizabeth O. Y. Lau and Allen T. Chwang, Fellow, ASCE "Relationship between Wrist-pulse Characteristics and Body Conditions" Department of Mechanical Engineering, The University of Hong Kong.

12. Katsuhiko Kohara, Yasuharu Tabara, Akira Oshiumi, Yoshinori Miyawaki, Tatsuya Kobayashi, and Tetsuro Miki "Radial

13. 13. P. Kallurkar, S. Sharma, K. Patil, and N. Sharma, "Nadi Diagnosis Techniques," International Journal Of Public Mental Health And Neurosciences, vol. 2, no. 1, pp. 17-23, Apr. 2015.

14. Roopini N, Joshi Manisha Shivaram, Shridhar, "Design \& Development of a System for Nadi Pariksha", International Journal of EngineeringResearch \& Technology 2015.

15. Parth Shah, A.V. Leio, Siddaram Mahajan, Shaik Jameel, "LabVIEW based Non-Invasive prototype device for cardiac diagnosis using Nadi Shastra", Department of Biomedical Engineering, SBST, Vellore Institute of Technology, Vellore, India, 2014.

16. A. Joshi, A. Kulkarni, S. Chandran, V. K. Jayaraman, and B. D. Kulkarni, Nadi tarangini, "A pulse based diagnostic system", Proceedings of the 29th Annual International Conference of the IEEE EMBS.

17. Jiann-Hwa Lue, Ting-Jou Ding, Yu-Sheng Su, Rong Seng Chang, Tai-Chuan Ko, Shuan-Yu Huang, Wen-Ming Cheng, "Low Cost Prototype of Pulse Measurement Devices”, life Science Journal 2014.

18. Rushikesh Pradip Kulkarni and Prof. Mahesh S. Kumbhar "Non-invasive method for diabetes detection using nadi pariksha and $A N N$ ” Rajarambapu Institute of Technology Sakharale, Maharashtra, ICCCES-16 june-2015.

19. Roopini N, Dr. Joshi Manisha Shivaram, Dr. Shridhar "Design \& Development of a System for Nadi Pariksha”, (IJERT) ISSN 2278-0181IJERTV4IS060509 Vol. 4 Issue 06, June-2015.

20. C. Narayanan, A. Dinesh Kumar, S. Priyadharshini\& S. Revathy," Cardiac disorder diagnosis through nadi (pulse) using piezoelectric sensors", (IJMRME) ISSN (Online): 2454 - 6119 Volume I, Issue I, 2015 . 


\section{AUTHORS PROFILE}

Narendra Kumar currently affiliated to R.N. Shetty Institute of Technology as Assistant professor, meanwhile he is pursuing his Ph.D. from Visveshwaraya Technological University. He has 18 years of teaching and 1 year of industrial experience. He has published books and also papers in International and National conferences. He has conducted several technical workshops and his areas of interest are Biomedical instrumentation, Embedded systems, Microcontrollers and OFC.

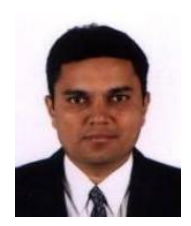

Second Author profile which contains their education Dr. K. B. Ramesh is currently affiliated to R.V College of Engineering, continuing research in the specialized scientific area of Digital Signal Processing. He is serving as an honorary reviewer for India \& other reputed journals and has authored articles along with chapters in different books related to Instrumentation Technology. He has 25 years of teaching and 8 years of research field experience. His area of interest are Signal Processing, Embedded System and Biomedical engineering. 